\title{
Hydrocarbon Based Analysis in Arson Cases Using Inflammable Materials
}

\author{
Joyeta Mitra* \\ Department of Forensic, India \\ Submission: April 23, 2018; Published: May 09, 2018 \\ *Corresponding author: Joyeta Mitra, Department of Forensic, India, Email: jmitra7290@gmail.com
}

\begin{abstract}
The point of this investigation is to examine hydrocarbon for the most part Polycyclic Aromatic Hydrocarbons (PAHs) in fire related crime cases utilizing diverse inflammable materials. Polycyclic Aromatic Hydrocarbons are hydrocarbon particles containing at least two aromatic rings. Some Polycyclic Aromatic Hydrocarbons are cancer-causing. PAHs are regularly found in the earth because of in part consumed natural materials, for example, oil, plastic, elastic, ointments and wood. This is a fundamental examination if there is doubt of pyro-crime. Any hints of potential accelerants in an example assumed from the position where the fire started are significant to an examination. The consequences of examination additionally constitute prove which can be utilized as a part of court. The examination of flame flotsam and jetsam in view of hydrocarbon in incendiaries cases has experienced a few exploratory stages.

The idea of investigation has been separated into three fundamental stages because of unpredictability of the examples. The first has been the extraction of the accelerants from the fire debris samples. The second has been the instrumental examination of the extracted samples and the last stage has been the translation of the outcomes. In my thesis, Gas Chromatography Mass Spectrometry (GC-MS) has been utilized. GC-MS is appropriate for the investigation of hydrocarbon accelerants. We connected the determination and partition energy of Mass Selective Detector to examine these accelerants for hydrocarbon investigation. By utilizing this procedure, we can convincingly decide the nearness of hydrocarbons which are Polycyclic Aromatic Hydrocarbons (PAHs) in the fire debris examination.
\end{abstract}

\section{Highlights}

a) It is possible to detect Poly Aromatic Hydrocarbons from inflammable materials.

b) Two Poly Aromatic Hydrocarbons were detected in three of the samples but they differ in quantity.

c) Poly aromatic hydrocarbons are generally carcinogenic and environmental pollutant.

Keywords: Accelerant; Arson case; Fire debris; Poly Aromatic Hydrocarbon, GC-MS

\section{Introduction}

Arson [1] to this day, one of the most frequently committed crimes. Arson can be defined as the intentional and malicious burning of someone's property for some improper purpose of gain. Arson cause not only serious material loses but also injury and death of several people. Arson is committed with criminal intent, arsons are generally committed out of revenge, to destroy criminal traces and evidences or to gain compensation fraudulently. If a fire breaks out in a suspicious manner, the site of the fire is investigated to determine if it was an accident or if it was started intentionally. An arson investigation usually starts by looking at the four factors that must be present in order to create and sustain a fire. These four factors are known as the fire tetrahedron. The fire tetrahedrons a four-sided geometric representation of the four factors necessary for fire: fuel that can be any substance that can undergo combustion reaction, heat to cause ignition, oxidizing agent (air containing oxygen), and uninhibited chemical chain reaction (sufficient exothermic reaction energy to produce ignition).

The fuel/air ratio must within flammable limits to propagate flame. Removing any of these four factors will prevent, suppress, or control the fire. In order to classify a fire as arson, the investigator has to prove tampering with at least one of the factors in the fire tetrahedron. Laboratory analysis of fire debris can encompass both physical and chemical examinations, but they are usually limited to searching for traces of accelerants which could have been used to start a fire. These include perfume, camphor and nail polish remover etc. widespread accelerants used in this trade are usually hydrocarbon accelerants. Debris from suspected arson fires are routinely analysed for trace amounts of hydrocarbon accelerants. The samples of debris are usually sealed at fire scene, in an airtight container that is glass bottles. Procedures for labelling the samples are given. The 
analysis is accomplished in three stages. The first stage consists of extraction of the suspected accelerants from the debris.

The second stage involves the instrumental analysis of extracted samples. Finally, the last stage involves the interpretation and analysis of results. Much of the research has gone into the first stage. Steam distillation and solvent extraction were historically the first methods used in the extraction and concentration of the suspected accelerated from the fire debris. Forensic investigators have searched for better methods for the separation of better methods for the separation of accelerants from the debris. It involved sampling by passive headspace with activated charcoal or solid phase micro extraction. Most sensitive methods are passive headspace with activated charcoal strips and solid phase micro extraction. For the analysis of fire debris ignitable residue samples gas chromatography mass spectrometry can be used. Polycyclic aromatic hydrocarbons [2]. (PAHs, also poly aromatic hydrocarbons or poly nuclear aromatic hydrocarbons) are hydrocarbons are organic compounds containing only carbon and hydrogen-that are composed of multiple aromatic rings (organic rings in which the electrons are delocalized). Formally, the class is further defined as lacking further branching substituents on these ring structures.

The simplest such chemicals are naphthalene, having two aromatic rings, and the three-ring compounds anthracite and phenanthrene. Many PAHs have toxic, mutagenic and/or carcinogenic properties. PAHs are highly lipid soluble and thus readily absorbed from the gastrointestinal tract of mammals. Atmospheric partitioning of $\mathrm{PAH}$ compounds between the particulate and the gaseous phases strongly influences their fate and transport in the atmosphere and the way they enter into the human body. It is the purpose of this study is to show that Gas Chromatography Mass Spectrometry [3]. Can be used in this type of investigation for hydrocarbon analysis purpose. As identification of traces of accelerants in fire debris is still a very difficult task, this is because accelerants are usually mixtures of many different chemical substances with different physical and chemical properties. But the resolution and separation power of GC-MS helped in the hydrocarbon-based analysis of flammable materials present in fire debris.

\section{Materials and Methods}

\section{Sampling}

Approximately $50 \mathrm{gm}$ of fire debris samples of inflammable materials such as nail polish remover, perfume and camphor were collected from India in 18th of February, 2018. Immediately, after collection the samples were sealed in air tight glass bottles which had been pre-washed with $\mathrm{n}$ - hexane and then transported to the ITS Laboratory, Noida, Uttar Pradesh- 201301 for analysis. In the laboratory, the samples were ground and mixed for 3 minutes in a shatter box in order to pass a 150-micro gram sieve. The ground sample was then split into several portions and stored into refrigerator for 72 hours. A sample of approximately
$100 \mathrm{mg}$ of fly ash was loaded into quartz crucible pre- washed with $\mathrm{n}$ - hexane and covered with aluminium foil until further processing and analysis Figure 1.

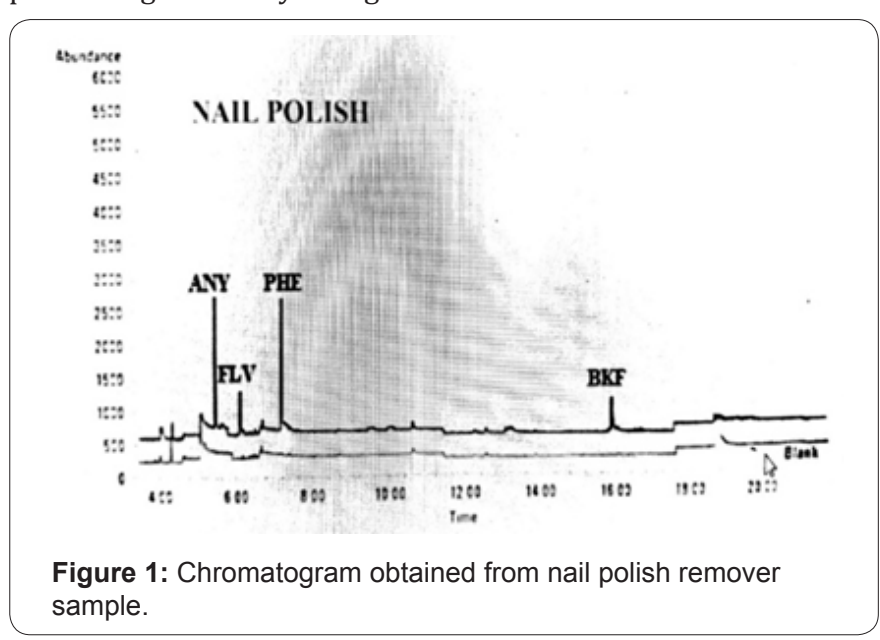

\section{Chemicals}

Standards of 16 Polycyclic Aromatic Hydrocarbons (PAHs) including Naphthalene, Acenaphthylene, Acenaphthene, Fluorene, Phenanthrene, Anthracene, Fluoranthene, Pyrene, Benzo (a) anthracene, Chrysene, Benzo (b) fluoranthene, Benzo (k) fluoranthene, Benzo (a) pyrene, Indenol (1,2,3-c, d) pyrene, Dibenzo (a, h) anthracene, Benzo (g, h, I) perylene were used. Standard PAH solutions were made by 2000 microgram $/ \mathrm{mL}$ each in ethylene chloride.

\section{Sample Extraction}

Samples were extracted using the following procedure. Briefly, one gram of each dry and homogenized sample was put into each clean centrifuge tube and a $1.1(\mathrm{v} / \mathrm{v})$ acetone/ n-hexane $(5 \mathrm{~mL})$ and surrogate standard mixture (2-fluorobiphenyl and 4-terphenyl-d14) solutions were then added into those tubes. Blanks were prepared following the same procedure without adding the samples. The standard sample used for quality control was prepared by adding the standard solution to $1: 1$ (v/v) acetone/ n-hexane. All samples were vortexes for 1 minute and the mixture was subjected to ultrasonic treatment for 15 minutes for PAH extraction. The sample tubes were then centrifuged at $2000 \mathrm{rpm}$ for 10 minutes. After centrifuging the organic layer containing the extracted compounds was siphoned out with a Pasteur Pipette and the sediment was restricted twice with $1: 1(\mathrm{v} / \mathrm{v})$ acetone/n-hexane $(5 \mathrm{~mL})$. All extracts were pooled together and activated copper was added to the combined extract for desulphurization. After subsequent drying over anhydrous sodium sulphate and concentration to $1.0 \mathrm{~mL}$ using a gentle stream of nitrogen, an internal standard mixture (naphthalene-d8), acetanaphthene-d10, phenanthrene-d10, chrysene-d12 and perylene-d12) solution was added to the extract to be analysed using gas chromatography with mass spectrometry detection. The main difference was that in my case the capillary column and GC analysis conditions are different. 


\section{GC-MS Instrumentation and Conditions}

An Agilent 6890N GC equipped with an Agilent 7683B Injector, a $30 \mathrm{~mm} \times 0.32 \mathrm{~mm}$ Hewlett- Packward-5 (HP-5MS) capillary column, coated with $5 \%$ phenyl - methyl siloxane (film thickness 0.25 micrometre) and an Agilent 5975 Mass Selective Detector (MSD) was used to separate and quantify the PAH compounds. The samples were injected in the split less mode at an injection temperature of 230-degree c. the transfer line temperature was 300-degree c. The interface temperature is 230-degree c. The column temperature was initially held at 70 -degree $\mathrm{c}$ for 1 minute. Then heated to 150 -degree $\mathrm{c}$ at 8-degree c per minute, then heated to 250-degree $\mathrm{c}$ at 5-degree c per minute and at finally heated to 300-degree $c$ at 7-degree $\mathrm{c}$ per minute and held for 5 minutes. Detector temperature was kept was 230-degree c. Helium was used as a carrier gas at a constant flow rate of $1 \mathrm{~mL} /$ Min. Mass spectrometry was acquired using electron ionization mode Figure 2.

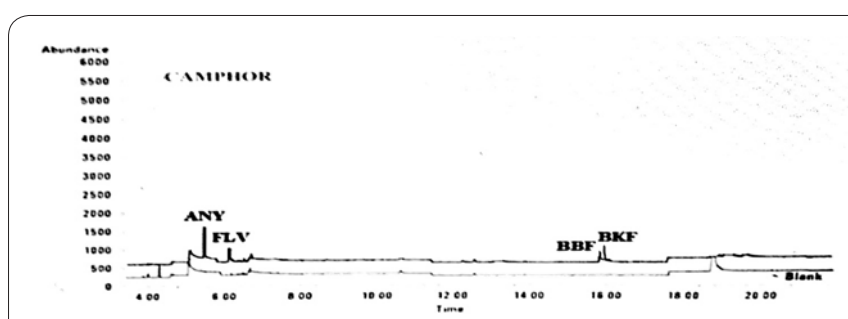

Figure 2: Chromatogram obtained from nail polish remover sample.

\section{Identification and Quantification}

Identity of PAHs in the samples was confirmed by the retention time and abundance of quantification in the authentic PAHs standards. In this study, sixteen priority PAHs were quantified from the each of fire debris containing three samples of nail polish remover, camphor and perfume using calibration curves for individual compounds.

\section{Results}

\section{Nail polish Remover Sample}

The (Table 1) indicates the test result of cloth sample burnt with nail polish remover. The inflammable material used was nail polish remover. When 16 parameters that is 16 PAHs were taken to analyse and quantification the result, then it was shown that 4 Polycyclic Aromatic Hydrocarbons were present in the sample. It was quantified from the GC-MS analysis that Acenaphthylene was quantified in the sample as $0.084 \mathrm{mg} / \mathrm{kg}$, Fluorene was quantified as $0.012 \mathrm{mg} / \mathrm{kg}$, Phenanthrene was quantified as $0.074 \mathrm{mg} / \mathrm{kg}$ and lastly Benzo (k) fluoranthene was quantified as $0.13 \mathrm{mg} / \mathrm{kg}$. Other PAHs are not detected in the nail polish remover sample of debris. The chromatogram, indicates the cloth sample burnt with nail polish remover indicates the presence of peaks of peaks of four PAHs such as acenaphthylene, fluorene, phenanthrene and benzo (k) fluoranthene. In this graph, relative abundance is on the y axis and retention time is on the $\mathrm{x}$ axis. Retention time is a measure of the time taken for a solute to pass through a chromatography column. It is calculated as the time taken from injection to detection.

Table 1: Quantity detected of PAH compounds in nail polish remover sample.

\begin{tabular}{|c|c|c|c|}
\hline Sl. No. & Compounds & Unit & Result \\
\hline 1. & Naphthalene & $\mathrm{mg} / \mathrm{kg}$ & N.D. \\
\hline 2. & Acenaphthylene & $\mathrm{mg} / \mathrm{kg}$ & 0.084 \\
\hline 3. & Acenaphthene & $\mathrm{mg} / \mathrm{kg}$ & N.D. \\
\hline 4. & Fluorene & $\mathrm{mg} / \mathrm{kg}$ & 0.012 \\
\hline 5. & Phenanthrene & $\mathrm{mg} / \mathrm{kg}$ & 0.074 \\
\hline 6. & Anthracene & $\mathrm{mg} / \mathrm{kg}$ & N.D. \\
\hline 7. & Fluoranthene & $\mathrm{mg} / \mathrm{kg}$ & N.D. \\
\hline 8. & Pyrene & $\mathrm{mg} / \mathrm{kg}$ & N.D. \\
\hline 9. & Benzo (a) anthracene & $\mathrm{mg} / \mathrm{kg}$ & N.D. \\
\hline 10. & $\begin{array}{c}\text { Chrysene } \\
\mathrm{mg} / \mathrm{kg}\end{array}$ & N.D. \\
\hline 11. & $\begin{array}{c}\text { Benzo (b) } \\
\text { fluoranthene }\end{array}$ & $\mathrm{mg} / \mathrm{kg}$ & N.D. \\
\hline 12. & $\begin{array}{c}\text { Benzo (k) } \\
\text { fluoranthene }\end{array}$ & $\mathrm{mg} / \mathrm{kg}$ & 0.13 \\
\hline 13. & Benzo (a) pyrene & $\mathrm{mg} / \mathrm{kg}$ & N.D. \\
\hline 14. & $\begin{array}{c}\text { Indenol (1,2,3-c, d) } \\
\text { pyrene }\end{array}$ & $\mathrm{mg} / \mathrm{kg}$ & N.D. \\
\hline 15. & $\begin{array}{c}\text { Dibenzo (a,h) } \\
\text { anthracene }\end{array}$ & $\mathrm{mg} / \mathrm{kg}$ & N.D. \\
\hline 16. & Benzo (g,h,i) perylene & $\mathrm{mg} / \mathrm{kg}$ & N.D. \\
\hline
\end{tabular}

\section{Camphor sample}

Table 2: Quantity detected of PAH compounds in camphor sample.

\begin{tabular}{|c|c|c|c|}
\hline Sl. No & Parameters & Unit & Result \\
\hline 1. & Naphthalene & $\mathrm{mg} / \mathrm{kg}$ & N.D. \\
\hline 2. & Acenaphthylene & $\mathrm{mg} / \mathrm{kg}$ & 0.036 \\
\hline 3. & Acenaphthene & $\mathrm{mg} / \mathrm{kg}$ & N.D. \\
\hline 4. & Fluorene & $\mathrm{mg} / \mathrm{kg}$ & 0.007 \\
\hline 5. & Phenanthrene & $\mathrm{mg} / \mathrm{kg}$ & N.D. \\
\hline 6. & Anthracene & $\mathrm{mg} / \mathrm{kg}$ & N.D. \\
\hline 7. & Fluoranthene & $\mathrm{mg} / \mathrm{kg}$ & N.D. \\
\hline 8. & Pyrene & $\mathrm{mg} / \mathrm{kg}$ & N.D. \\
\hline 9. & $\begin{array}{l}\text { Benzo (a) } \\
\text { anthracene }\end{array}$ & $\mathrm{mg} / \mathrm{kg}$ & N.D. \\
\hline 10. & Chrysene & $\mathrm{mg} / \mathrm{kg}$ & N.D. \\
\hline 11. & $\begin{array}{l}\text { Benzo (b) } \\
\text { fluoranthene }\end{array}$ & $\mathrm{mg} / \mathrm{kg}$ & 0.08 \\
\hline 12. & $\begin{array}{c}\text { Benzo (k) } \\
\text { fluoranthene }\end{array}$ & $\mathrm{mg} / \mathrm{kg}$ & 0.11 \\
\hline 13. & Benzo (a) pyrene & $\mathrm{mg} / \mathrm{kg}$ & N.D. \\
\hline 14. & $\begin{array}{c}\text { Indenol }(1,2,3-\mathrm{c}, \mathrm{d}) \\
\text { pyrene }\end{array}$ & $\mathrm{mg} / \mathrm{kg}$ & N.D. \\
\hline 15. & $\begin{array}{l}\text { Dibenzo }(\mathrm{a}, \mathrm{h}) \\
\text { anthracene }\end{array}$ & $\mathrm{mg} / \mathrm{kg}$ & N.D. \\
\hline 16. & $\begin{array}{l}\text { Benzo }(\mathrm{g}, \mathrm{h}, \mathrm{i}) \\
\text { perylene }\end{array}$ & $\mathrm{mg} / \mathrm{kg}$ & N.D. \\
\hline
\end{tabular}


The Table 2 indicates the test result of cloth sample burnt with camphor. The inflammable material used was camphor. When 16 parameters that is 16 PAHs were taken to analyse and quantification the result, then it was shown that 4 Polycyclic Aromatic Hydrocarbons were present in the sample. It was quantified from the GC-MS analysis that Acenaphthylene was quantified in the sample as $0.036 \mathrm{mg} / \mathrm{kg}$, Fluorene was quantified as $0.007 \mathrm{mg} / \mathrm{kg}$, Benzo (b) fluoranthene was quantified as 0.08 $\mathrm{mg} / \mathrm{kg}$ and lastly Benzo (k) fluoranthene was quantified as $0.11 \mathrm{mg} / \mathrm{kg}$. Other PAHs are not detected in the camphor sample of debris.

The chromatogram, indicates the cloth sample burnt with camphor indicates the presence of peaks of four PAHs such as acenaphthylene, fluorene, benzo (b) fluoranthene and benzo (k) fluoranthene. In this graph, relative abundance is on the $y$ axis and retention time is on the $\mathrm{x}$ axis. Retention time is a measure of the time taken for a solute to pass through a chromatography column. It is calculated as the time taken from injection to detection.

\section{Perfume Sample}

Table 3: Quantity detected of PAH compounds in perfume sample.

\begin{tabular}{|c|c|c|c|}
\hline Sl. No & Parameters & Unit & Result \\
\hline 1. & Naphthalene & $\mathrm{mg} / \mathrm{kg}$ & N.D. \\
\hline 2. & Acenaphthylene & $\mathrm{mg} / \mathrm{kg}$ & 0.11 \\
\hline 3. & Acenaphthene & $\mathrm{mg} / \mathrm{kg}$ & N.D. \\
\hline 4. & Fluorene & $\mathrm{mg} / \mathrm{kg}$ & 0.06 \\
\hline 5. & Phenanthrene & $\mathrm{mg} / \mathrm{kg}$ & N.D. \\
\hline 6. & Anthracene & $\mathrm{mg} / \mathrm{kg}$ & N.D. \\
\hline 7. & Fluoranthene & $\mathrm{mg} / \mathrm{kg}$ & N.D. \\
\hline 8. & Pyrene & $\mathrm{mg} / \mathrm{kg}$ & N.D. \\
\hline 9. & Benzo (a) anthracene & $\mathrm{mg} / \mathrm{kg}$ & N.D. \\
\hline 10. & Chrysene & $\mathrm{mg} / \mathrm{kg}$ & N.D. \\
\hline 11. & $\begin{array}{c}\text { Benzo (b) } \\
\text { fluoranthene }\end{array}$ & $\mathrm{mg} / \mathrm{kg}$ & N.D. \\
\hline 12. & $\begin{array}{c}\text { Benzo }(\mathrm{k}) \\
\text { fluoranthene }\end{array}$ & $\mathrm{mg} / \mathrm{kg}$ & N.D. \\
\hline 13. & Benzo (a) pyrene & $\mathrm{mg} / \mathrm{kg}$ & N.D. \\
\hline 14. & $\begin{array}{c}\text { Indenol }(1,2,3-c, d) \\
\text { pyrene }\end{array}$ & $\mathrm{mg} / \mathrm{kg}$ & 0.017 \\
\hline 15. & $\begin{array}{c}\text { Dibenzo (a,h) } \\
\text { anthracene }\end{array}$ & $\mathrm{mg} / \mathrm{kg}$ & 0.047 \\
\hline 16. & Benzo (g,h,i) perylene & $\mathrm{mg} / \mathrm{kg}$ & N.D. \\
\hline
\end{tabular}

The Table 3 indicates the test result of cloth sample burnt with perfume. The inflammable material used was perfume. When 16 parameters that are 16 PAHs were taken to analyse and quantification the result, then it was shown that 4 Polycyclic Aromatic Hydrocarbons were present in the sample. It was quantified from the GC-MS analysis that Acenaphthylene was quantified in the sample as $0.11 \mathrm{mg} / \mathrm{kg}$, Fluorene was quantified as $0.06 \mathrm{mg} / \mathrm{kg}$, Indenol $(1,2,3-\mathrm{c}, \mathrm{d})$ pyrene was quantified as
$0.017 \mathrm{mg} / \mathrm{kg}$ and lastly Dibenzo $(\mathrm{a}, \mathrm{h})$ anthracene was quantified as $0.047 \mathrm{mg} / \mathrm{kg}$. Other PAHs are not detected in the perfume sample of debris.

The chromatogram, Figure 3 indicates the cloth sample burnt with perfume indicates the presence of peaks of four PAHs such as acenaphthylene, fluorine, Indenol (1, 2, 3-c,d) pyrene and Dibenzo $(\mathrm{a}, \mathrm{h})$ anthracene. In this graph, relative abundance is on the $\mathrm{y}$ axis and retention time is on the $\mathrm{x}$ axis. Retention time is a measure of the time taken for a salute to pass through a chromatography column. It is calculated as the time taken from injection to detection.

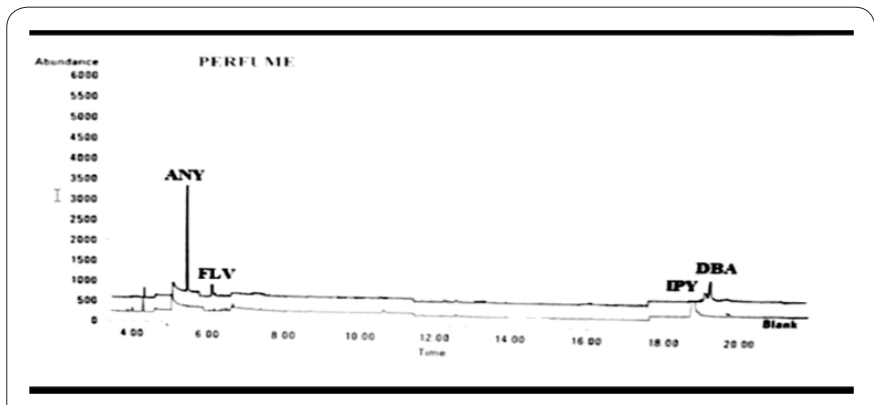

Figure 3: Chromatogram obtained from perfume sample.

\section{Discussion}

In three samples of fire debris, among the detected samples, two Poly Aromatic Hydrocarbons were commonly detected, and they are Acenaphthylene and Fluorene. But when the results of two fire debris sample of Nail Polish Remover and Camphor were compared then it has been seen that Poly Aromatic Hydrocarbon Compound Benzo (k) fluoranthene were present in both the samples of Nail Polish Remover and Camphor. Acenaphthylene is a solid and used for research purposes. Blood Polycyclic Aromatic Hydrocarbon (PAH) levels in children, including Acenaphthylene, significantly correlated with oxidative stress and altered antioxidant status. This is an environmental contaminant formed from combustion products of fossil fuels, grilled smoke foods. Fluorene is a polycyclic aromatic hydrocarbon. It forms white crystals that exhibit a characteristic, aromatic odour similar to that of naphthalene. When quantification of those two Polycyclic Aromatic Hydrocarbons was done, then it seems that those two polycyclic aromatic hydrocarbons differ in amount of quantity.

By comparative analysis of those two compounds of PAHs Acenaphthylene and Fluorene [37], it can be included that which fire debris sample contains more amount of Acenaphthylene and which sample contains fewer amounts. Again, for the compound of PAH that is Fluorene, comparative analysis is done and again it can be concluded that which fire debris sample contains more amount of Fluorene and which contains the less amount. About the comparative analysis of PAH compound of Acenaphthylene present in three samples of nail polish remover, camphor and perfume. According to the chart 4, Acenaphthylene present in large quantity in perfume sample. After perfume sample, Acenaphthylene present inlarge amount in the nail polish 
remover sample. And less amount of Acenaphthylene is present in the camphor sample. In nail polish remover sample the amount of Acenaphthylene is $0.084 \mathrm{mg} / \mathrm{kg}$, in camphor sample the amount is $0.036 \mathrm{mg} / \mathrm{kg}$ and finally in the perfume sample the amount of Acenaphthylene is $0.11 \mathrm{mg} / \mathrm{kg}$.

About the comparative analysis of PAH compound of Fluorene present in three samples of nail polish remover, camphor and perfume. According to the chart 5, Fluorene present in large quantity in camphor sample. After camphor sample, Fluorene present in more amount in the perfume sample. And most less amount of Fluorene is present in the nail polish remover sample. In nail polish remover sample the amount of Fluorene is 0.012 $\mathrm{mg} / \mathrm{kg}$, in camphor sample the amount is $0.07 \mathrm{mg} / \mathrm{kg}$ and finally in the perfume sample the amount of Fluorene is $0.06 \mathrm{mg} / \mathrm{kg}$. About the comparative analysis of PAH compound of Benzo (k) Fluoranthene present in two samples of nail polish remover, camphor. According to the chart 5, Benzo (k) Fluoranthene present in large quantity in nail polish remover sample. After nail polish remover sample, Benzo (k) Fluoranthene present in less amount in the camphor sample. But in perfume sample Benzo (k) Fluoranthene is not detected. In nail polish remover sample the amount of Benzo (k) fluoranthene is $0.13 \mathrm{mg} / \mathrm{kg}$, in camphor sample the amount is $0.11 \mathrm{mg} / \mathrm{kg}$.

\section{Conclusion}

An effective sample preparation technique was developed for the analysis of hydrocarbons from the three fire debris samples of nail polish remover, camphor and perfume. Most of the Polycyclic Aromatic Hydrocarbons are carcinogenic and they are environmental pollutants and they are generally formed by incomplete combustion of inflammable materials such as wood, coal tar, camphor, perfume. It was also reported that all of the three samples contained Polycyclic Aromatic Hydrocarbons (PAHs) such as Acenaphthylene and Fluorene, but in different amount. The retention time for the above two hydrocarbons were the same but the abundance of quantification/confirmation ions for the above two Polycyclic Aromatic Hydrocarbons (PAHs) were different. The basis of this analysis was to quantify the amount of Polycyclic Aromatic Hydrocarbons in the fire debris samples when the cloth sample is burnt with three different samples such as Nail Polish Remover, Camphor and Perfume. This analysis helped to identify the toxic Polycyclic Aromatic Hydrocarbons which are generally produced in arson cases which can be very much harmful pollutant and also their amount was quantified. The results should be useful in determining that these inflammable materials should not be used as they produce harmful pollutants and they are really toxic and even they can also cause cancer and cause problems in pregnant women and they are also responsible for mutagenic properties.

\section{References}

1. White J, Dalby JT (2000) Arson. In: D.s Mercer, T. Mason, M. McKeown, G. McCann (Eds) Forensic Mental Health Care. Edinburgh: Churchill Livingston.

2. Harvey RG (1998) Environmental Chemistry of PAHs. PAHs and Related Compounds: Chemistry. The Handbook of Environmental Chemistry.

3. David Sparkman 0, Zelda Penton, Fulto Kitson (2011) Gas Chromatography and Mass Spectrometry: A Practical Guide.

This work is licensed under Creative Commons Attribution 4.0 License

DOI: 10.19080/JFSCI.2018.08.555740
Your next submission with Juniper Publishers will reach you the below assets

- Quality Editorial service

- Swift Peer Review

- Reprints availability

- E-prints Service

- Manuscript Podcast for convenient understanding

- Global attainment for your research

- Manuscript accessibility in different formats ( Pdf, E-pub, Full Text, Audio)

- Unceasing customer service

Track the below URL for one-step submission https://juniperpublishers.com/online-submission.php 